\title{
Morphometry Research of Deer, Sheep, and Human Lumbar Spine: Feasibility of Using Deer and Sheep in Spinal Animal Models
}

\author{
Investigación Morfometríca de la Columna Vertebral Lumbar de Ciervos, Ovejas y Humanos: \\ Factibilidad del Uso de Ciervos y Ovejas como Modelos Animales de Columna Vertebral
}

"Xiaofan Bai; *Guomin Liu; " Chuanjie Xu; ${ }^{* * *}$ Yingying Zhuang; ${ }^{* * * *}$ Jinlong Zhang; ${ }^{* * * * *}$ Yuyan Jia \& Yi Liu

BAI, X.; LIU, G.; XU, C.; ZHUANG, Y.; ZHANG, J.; JIA, J. \& LIU, Y. Morphometry research of deer, sheep, and human lumbar spine: feasibility of using deer and sheep in spinal animal models. Int. J. Morphol., 30(2):510-520, 2012.

SUMMARY: Deer and sheep are used as spinal animal models in clinical and basic research. In this paper, the anatomical morphology, curvature, and morphology index parameters were investigated to assess the feasibility of using deer and sheep as animal models of the human spine. Fresh adult male sheep, deer, and human spine specimens $(\mathrm{n}=10$ each) were screened and subjected to morphological analyses. The statistical software package SPSS (version 17.0) was used to analyze the statistical similarity and variability among the 3 species. Deer displayed good similarity to human in terms of the vertebral transverse diameter, radius vector, spinal canal transverse diameter, radius vector, and vertebral upper and lower endplate curvature radii. Sheep displayed good similarity to human in terms of the vertebral body height, pedicle height, vertebral mid-lever curvature radius, and vertebral positive curvature radius. Human, deer, and sheep each displayed unique morphological characteristics and trends for the lumbar spine. These findings indicate that deer and sheep are good spinal animal models of human in morphometry, but with specific advantages in different research fields: deer are more suitable when studying vertebrae and endplate structures, while sheep are more suitable when referring to structures such as the vertebral walls.

KEY WORDS: Lumbar spine; Animal model; Human; Deer; Sheep; Morphometry.

\section{INTRODUCTION}

The research and development of surgical instruments, such as the spinal surgery inner fixer, have improved spinal surgery and operation methods. However, before applying various inner fixers and operation methods, animal experiments must be performed to assess the clinical feasibility. Animal models have become an important research method for spinal surgery. The animal model used should have good similarity and comparability to human (Schimandle \& Boden, 1994).

To date, animals such as calf, goat, and sheep have been used widely in spinal surgery (Kettler et al., 2007; Sandén et al., 2001; Wilke et al., 1997; Yildirim et al., 2006). Some studies also have used dog and pig (Christensen et al., 2000; Matsuzaki et al., 1997). However, recent outbreaks of bovine spongiform encephalopathy, avian influenza, SARS, and influenza A (H1N1) have restricted use of these animals in the medical field due to the potential dangers of human transmission. In contrast, there have been fewer reported cases of deer as zoonosis carriers. Although deer have good compatibility in form and quality with human, research in this field is lacking. Kumar et al. (2000) first recommended the use of deer as an animal model in 2000, but their research was confined to simple measurements of various anatomical lines and angles.

The purpose of the present study was to assess the feasibility of using deer or sheep as an animal model for the human spine. Using simple anatomical measurements, morphological index and curvature parameters reflecting the vertebral morphometry of deer and sheep were compared to measurements in human.

\section{MATERIAL AND METHOD}

The following specimens were screened: 10 adult female deer (Cervus nippon) (age: 1.5-2 years, body length: $75-95 \mathrm{~cm}$, and weight: $75-85 \mathrm{~kg}$ ); 10 male Mongolia sheep

* Department of Orthopedics, the Second Hospital of Jilin University, Changchun, China.

** Department of Pathology, the Second Hospital of Jilin University, China.

*** Department of Anesthesiology, the Tang Du Hospital of the Fourth Military Medical University, China.

***** Department of Orthopedics, the forth Hospital of Jilin University, Changchun, China.

****** Department of Traumatology, the Changchun College of Traditional Chinese Medicine, Changchu, China. 
(age: $1.5-2$ years, body length: $52-79 \mathrm{~cm}$, and weight: $46-62$ $\mathrm{kg}$ ); and 10 fresh male human cadavers (age: 21-39 years and height: $168-177 \mathrm{~cm})$. Deer and sheep were killed with excess pentobarbital sodium to obtain 10 lumbar spine specimens from each species (Fig. 1). These specimens, together with 10 human lumbar spine specimens, were screened by X-ray to eliminate visible lesions. All specimens were packaged in plastic film bags and stored at $-20{ }^{\circ} \mathrm{C}$ until use (Seldin \& Hirsch, 1966).

Before testing, the specimens were thawed at room temperature. Soft tissues around the specimens were removed and the discs and ligaments were retained. The specimens were scanned by computed tomography (CT) and measured with a caliper. All screening, collection, and treating processes were performed according to the National Standards for Laboratory Animals (1997).

Measurement of Curvature Radii. The 64-row CT presentation was used to reconstruct the three-dimensional anatomical structure of the lumbar spine.

To measure the vertebral upper and lower endplate and mid-lever curvature radii (ECRu, ECRl, and VCRml, respectively), the transverse and sagittal diameters of the upper surface, lower surface, and mid-lever of the lumbar spine were used to divide the corresponding lever into 4 quadrants. Using the Auto CAD2006 drawing software, the endplate edge curvature radii of the 2 anterior quadrants were measured.

To measure the vertebral positive curvature radius (VCRp), the vertebra was cut via coronal sections through the midpoints of the VSDs and VSDi. The curvature radius of the vertebral right margin was measured.

To measure the lateral vertebral curvature radius (VCRl), the vertebra was cut via coronal sections through the midpoints of the VSDs and VSDi. The curvature radius of the vertebral front margin was measured.

Linear Measurements. Using a vernier caliper $(0.02 \mathrm{~mm}$ accuracy) as a measuring tool, symmetrical vertebral structures were measured on the right side only according to the various radial line measurement standards and methods found in Shao's Anthropometric Manual (Shao, 1985).

The anterior vertebral body height (VBHa) was measured on the median sagittal plane as the straight distance between the upper and lower margins of the vertebral ventral surface. The center VBH (VBHc) was measured as the straight distance between the midpoints of the upper and lower vertebral surfaces. The posterior VBH (VBHp) was measured on the median sagittal plane as the straight distance between the upper and lower margins of the vertebral dorsal surface.

The superior vertebral transverse diameter (VTDs) was measured on the upper surface as the straight distance between the most prominent points of the left and right sides. The center VTD (VTDc) was measured as the minimal distance between the left and right sides in the middle lever. The inferior VTD (VTDi) was measured on the lower surface as the straight distance between the most prominent points of the left and right sides.

The VSDs was measured as the straight distance between the front and back intersection nodes of the upper surface and the median sagittal plane. The center VSD (VSDc) was measured on the median sagittal plane as the sagittal diameter of the vertebral central region. The VSDi was measured as the straight distance between the front and back intersection nodes of the lower surface and the median sagittal plane.

The spinal canal transverse (SCTD) and sagittal
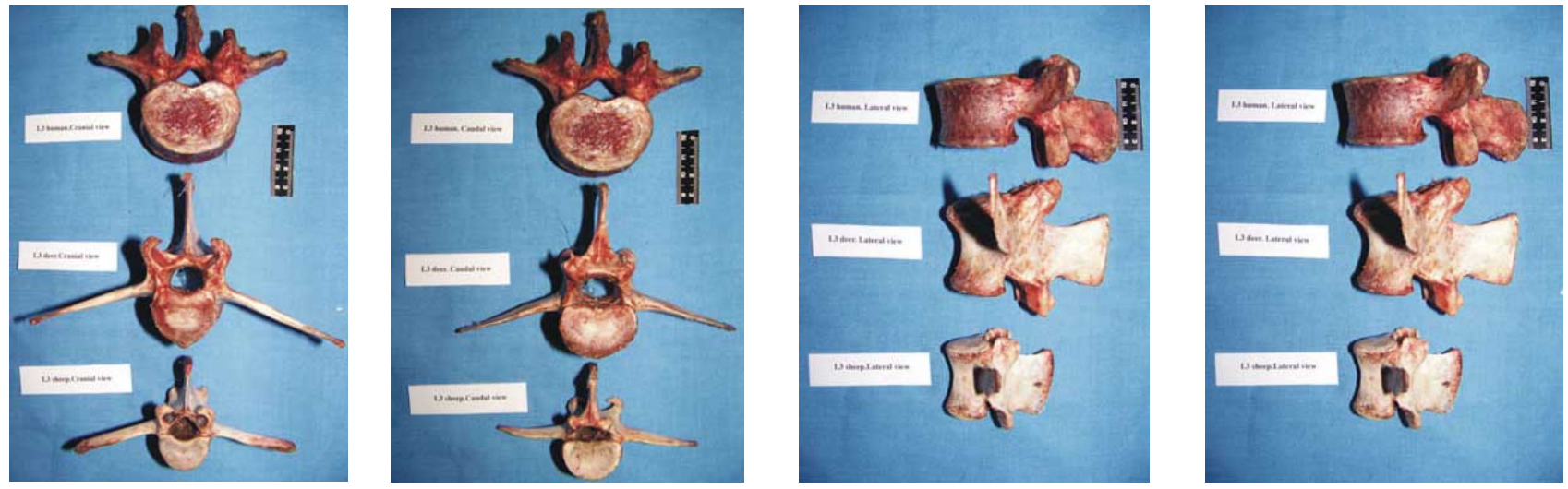

Fig. 1. Lumbar morphometry. From top to bottom are human, deer, and sheep. 
(SCSD) diameters were measured as the maximum transverse and sagittal diameters, respectively, of the spinal canal. The pedicle height (PDH) was measured as the maximum distance between the superior and inferior vertebral notches. The pedicle width (PDW) was measured as the maximum distance between the pedicle side wall and the spinal canal wall.

Calculation of Vertebral Indices. The vertebral index is an objective index used to describe the vertebral body shape.

The vertebral vertical index (VVI) was defined as $\mathrm{VVI}=\mathrm{VBHp} / \mathrm{VBHa} * 100$. This index reflected the morphological foundation of the spinal physiological curvature, which was defined as a dorsal wedge type for VVI values <97.9, straight type for values of 98.0-101.9, and ventral wedge type for values $>102.0$ (Vialle et al., 2007).

The central vertebral index (CVI) was defined CVI $=\mathrm{VSDc} / \mathrm{VTDc} * 100$. This index reflected the shape of the vertebral plane, which was considered to be triangular for index values of 50-80, circular for values of $80-90$, and subcircular for values $>90$.

The spinal canal index $(\mathrm{SCI})$ was defined as $\mathrm{SCI}=$ $\mathrm{SCSD} / \mathrm{SCTD} * 100$. This index reflected the shape of the spinal canal plane, which was considered to be triangular for index values of 50-80, circular for values of 80-90, and subcircular for values >90 (Bai et al., 1980).

The pedicle aspect ratio (PAR) was defined as PAR $=\mathrm{PDW} / \mathrm{PDH} * 100$. The PAR reflected the shape of the pedicle coronal section, which was considered to be boardform for PAR values $<50$, triangular for values of 50-80, circular for values of 80-90, and subcircular for values $>90$ (Qiao \& Han, 1996).

\section{RESULTS}

\section{Linear Measurement}

VBH: The VBHc and VBHp of the human lumbar spine showed gradually descending trends with increasing lumbar vertebral lumbar ordinal number, while VBHa showed an increasing trend $(\mathrm{P}>0.05)$. This change is consistent with the flexure of the human lumbar spine. For deer and sheep, the VBHa, VBHc, and VBHp values all showed roughly increasing trends with increasing vertebral ordinal number $(\mathrm{P}>0.05)$. Marked differences were seen between the VBH results of deer, sheep, and human $(\mathrm{P}<0.01)$. The $\mathrm{VBH}$ values were largest for deer, followed by those of sheep and human.

Table I. Anatomical parameters and their abbreviations.

\begin{tabular}{lcl}
\hline & Abbreviations & \multicolumn{1}{c}{ Dimension } \\
\hline Vertebral body & VBH & Vertebral body height \\
VSD & Vertebral sagittal diameter \\
VTD & Vertebral transverse diameter \\
VVI & Vertebral vertical index \\
Pedicle & PDW & Pedicle width \\
& PDH & Pedicle height \\
Vertebral morphology & PAR & Pedicle aspect ratio \\
curvature radius & CR & Curvature radius \\
& ECR & Endplate curvature radius \\
VCR & Vertebral curvature radius \\
Spinal canal & VCRp & Vertebral positive curvature radius \\
VCRl & Vertebral lateral curvature radius \\
& SCTD & Spinal canal transverse diameter \\
& SCSD & Spinal canal sagittal diameter \\
& a, c, or p & Anterior, center, or posterior \\
s, ml, or i & Superior, middle, or inferior \\
& u or l & Upper or lower \\
\hline
\end{tabular}

VTD: The VTD values showed an increasing trend $(P>0.05)$ from $L 1$ to L5 for deer, sheep, and human. Significant differences existed among the groups for VTDs $(\mathrm{P}<$ $0.01)$, VTDi $(\mathrm{P}<0.01)$, and VTDc $(\mathrm{P}<0.05)$. The VTDi and VTDc of human were largest, followed by those of deer and sheep.

VSD: Significant differences in the VSDs, VSDc, and VSDi values were observed among human, deer, and sheep $(\mathrm{P}<0.01)$. The values in human were the largest, followed by those in deer and sheep.

CVI: The CVI values of human, deer, and sheep were all $<0.8$ (triangular). The CVI values for deer were more similar to those of human than were the CVI values of sheep $(\mathrm{P}<0.01)$. 


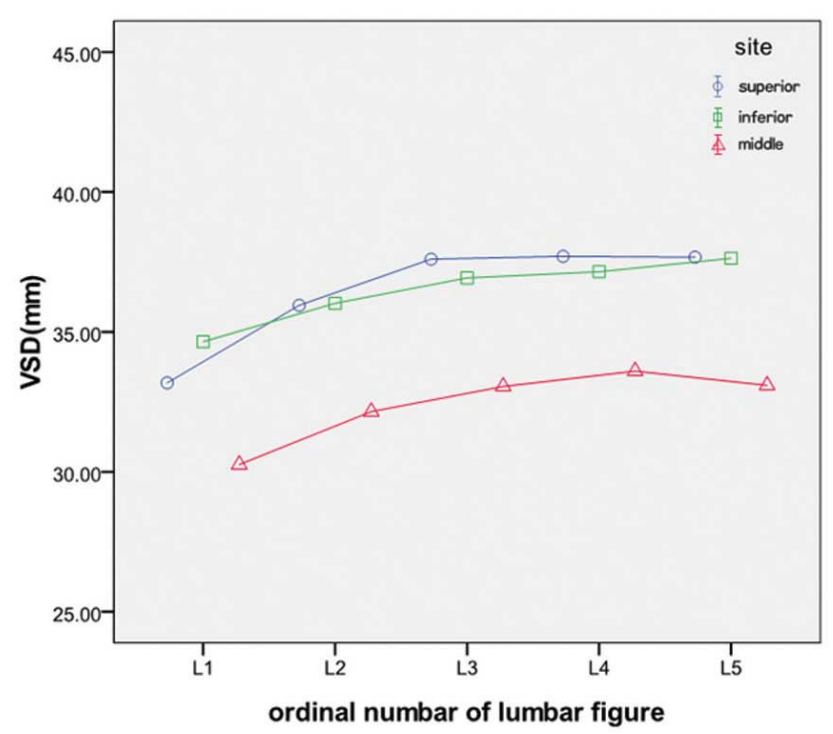

Fig. 2. Trend of VSDu, VSDm, and VSDi of human. Blue line: VSDu; red line: VSDm; green line: VSDi.

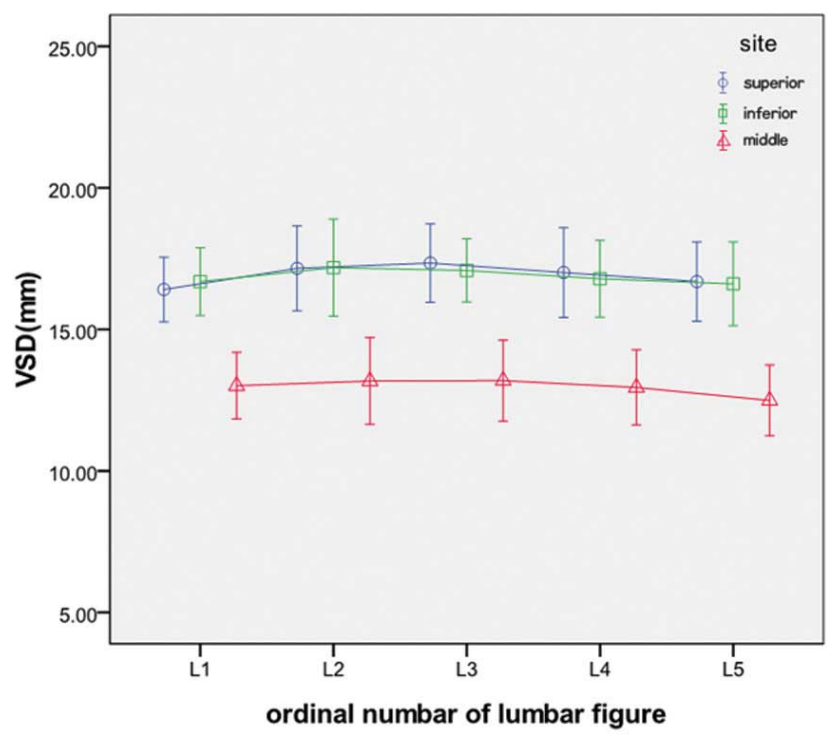

Fig. 4. Trend of VSDu, VSDm, and VSDi of sheep. Blue line: VSDu; red line: VSDm; green line: VSDi.

Spinal canal: Significant differences in the SCTD and SCSD values were observed among. The values were largest for human, followed by those of deer and sheep.

Pedicle: Significant differences in the PDH values were observed among the 3 species $(\mathrm{P}<0.01)$. The $\mathrm{PDH}$ values were largest for deer, followed by sheep and human. There was also a remarkable difference in the PDW values among the 3 species $(\mathrm{P}<0.01)$. The PDW values were largest for human, followed by deer and sheep.

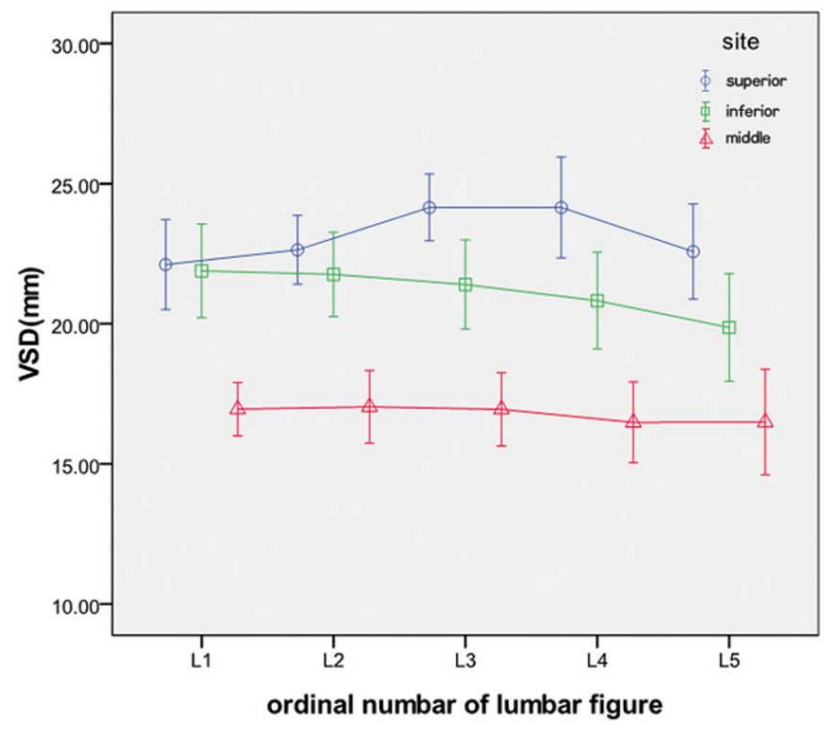

Fig. 3. Trend of VSDu, VSDm, and VSDi of deer. Blue line: VSDu; red line: VSDm; green line: VSDi.

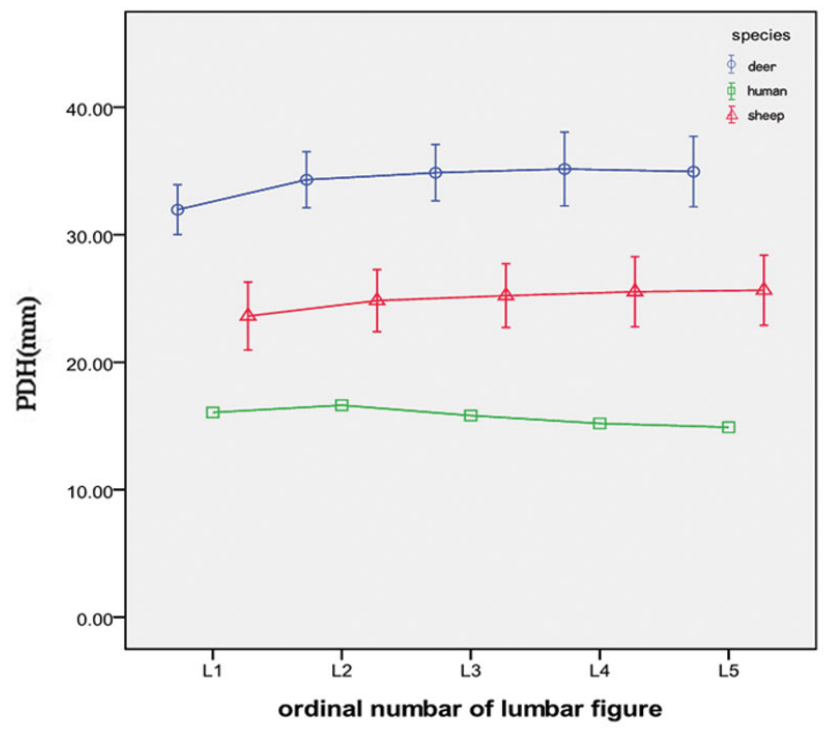

Fig. 5. Comparison of PDH of human, deer, and sheep. Blue line: deer; red line: sheep; green line: human.

PAR: The PAR of human showed a gradually increasing trend with increasing ordinal number of the lumbar vertebrae. The PAR values of deer and sheep were similar. The variation tendency of PAR was quite consistent among the species $(\mathrm{P}>0.05)$.

\section{Measurement of CR}

ECRu, ECRI, and VCRml: The ECRu and ECRl values of human, deer, and sheep showed gradually increasing trends with increasing vertebral ordinal number. The ECRu and 


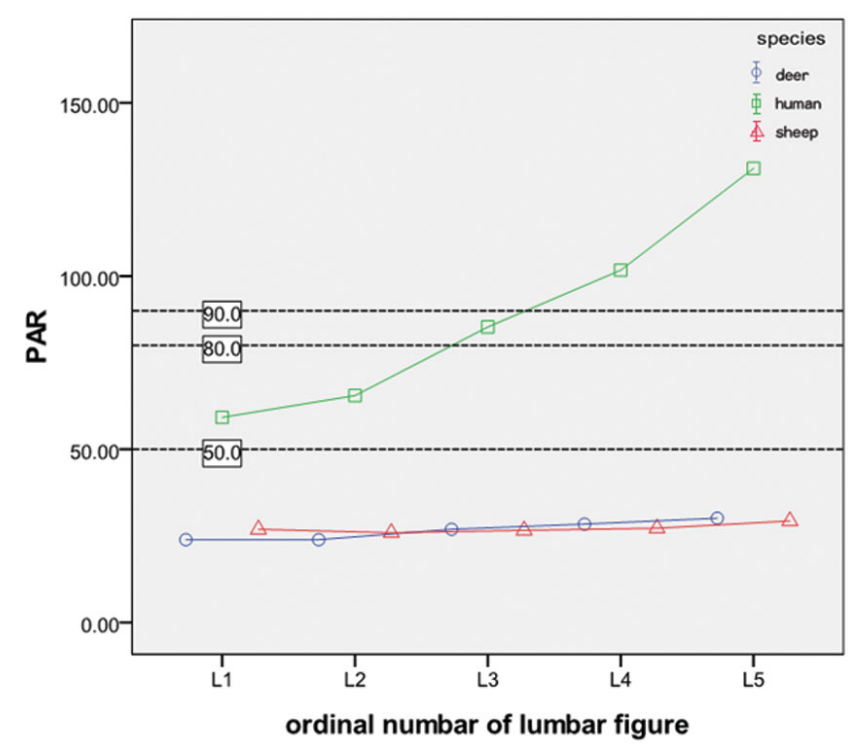

Fig. 6. Comparison of PAR of human, deer, and sheep. Blue line: deer; red line: sheep; green line: human.

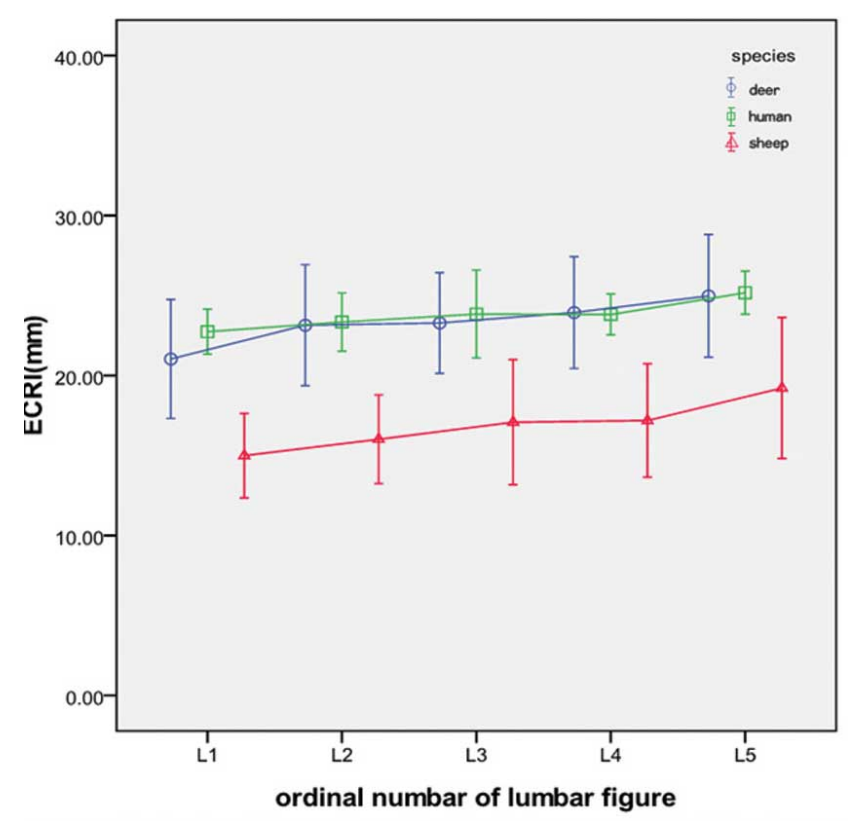

Fig. 8. Comparison of ECRi of human, deer, and sheep. Blue line: deer; red line: sheep; green line: human.

ECR1 values of deer and sheep were not significantly different $(\mathrm{P}>0.05)$. In human, the VCRml values were less than the ECRu and ECRl values, and gradually increased from $\mathrm{L} 1$ to L5 ( $\mathrm{P}>0.05)$. In deer, the VCRml values were larger than the ECRu and ECRl values, and gradually decreased from $L 1$ to $L 5(P>0.05)$. The sheep lumbar spine was similar to human in the variation tendency of VCRml and the relationship between ECRu and ECRl (Fig. 9).

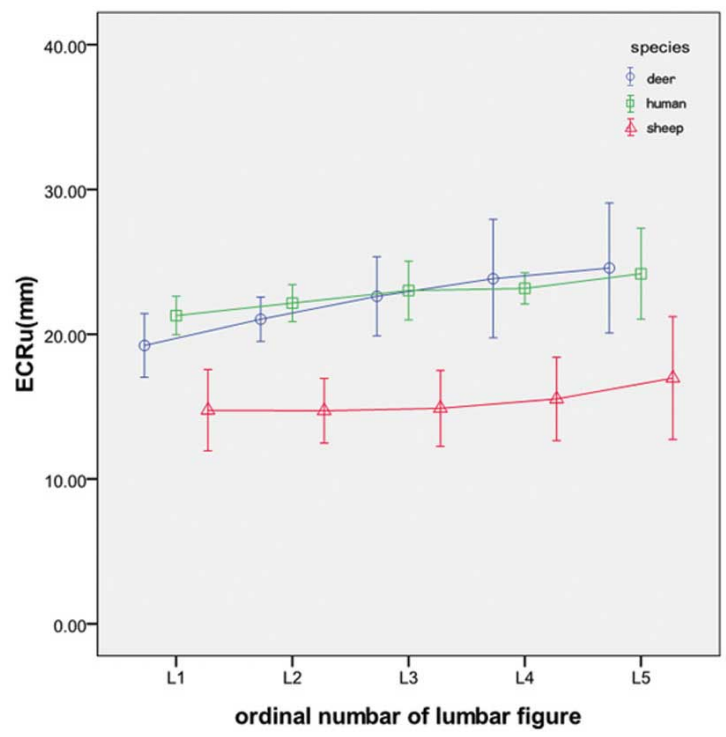

Fig. 7. Comparison of ECRu of human, deer, and sheep. Blue line: deer; red line: sheep; green line: human.

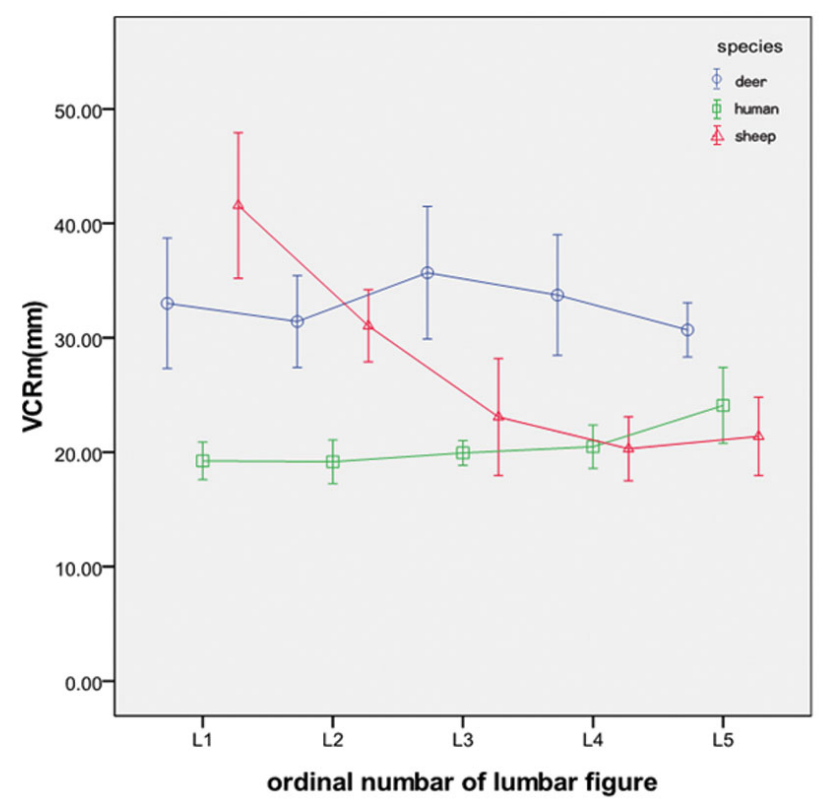

Fig. 9. Comparison of ECRml of human, deer, and sheep. Blue line: deer; red line: sheep; green line: human.

Compared to deer, the VCRml of sheep lumbar spine was closer to that of human $(\mathrm{P}>0.05)$.

VCRp: The VCRp values in human showed a roughly increasing trend from L1 to L5. From L1 to L4 of deer and L1 to L3 of sheep, VCRp showed a similar increasing trend. The VCRp of sheep was closer to that of human than was the deer VCRp $(\mathrm{P}>0.05)$. 


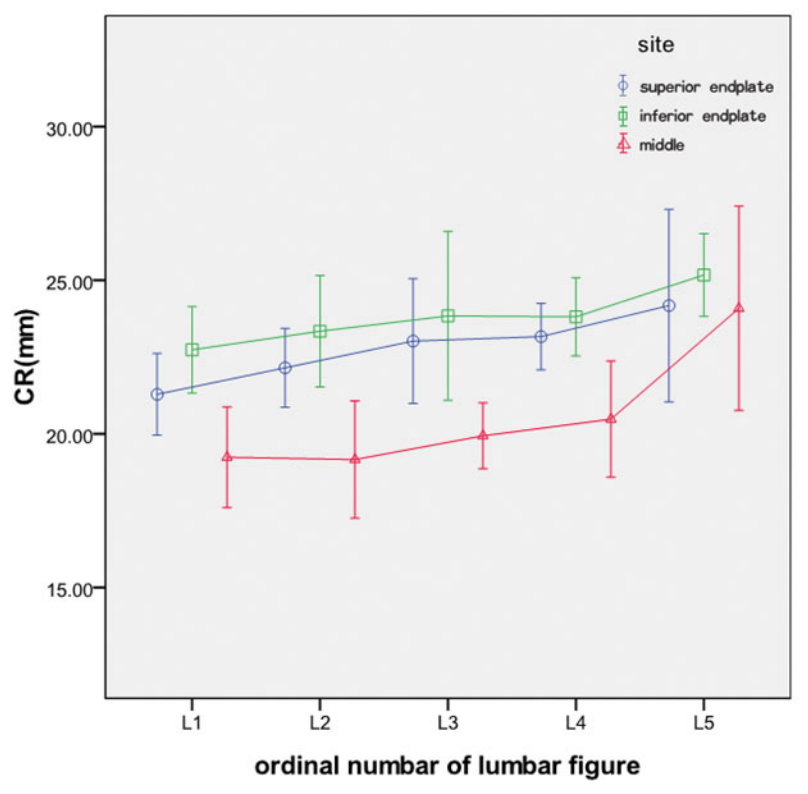

Fig. 10. Comparison of ECRu, ECRi, and VCRml of human. Blue line: $\mathrm{ECRu}$; red line: VCRm; green line: ECRi.

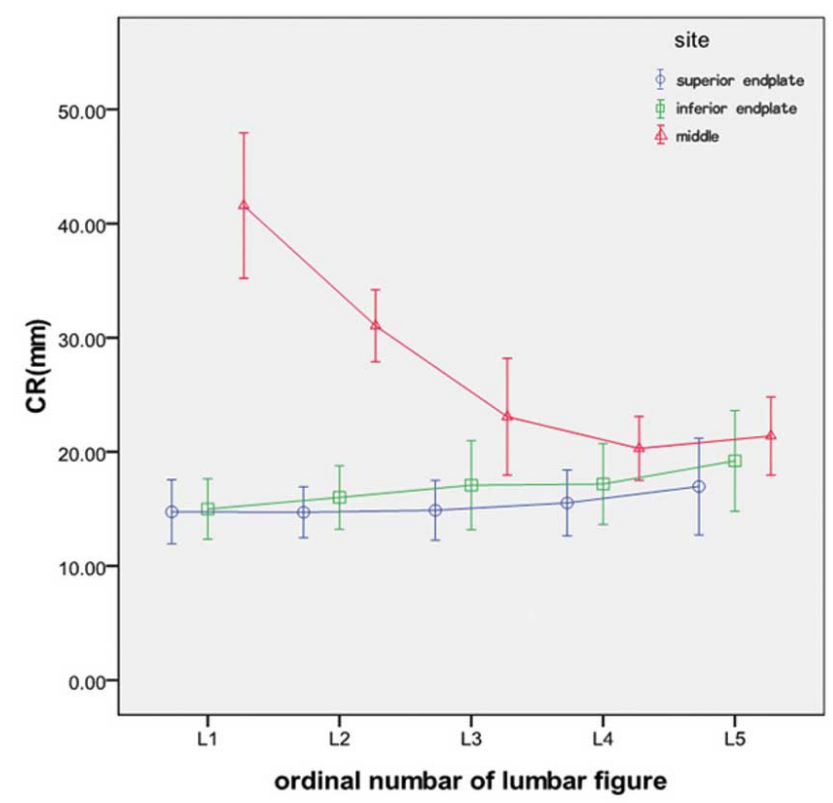

Fig. 12. Comparison of ECRu, ECRi, and VCRml of sheep. Blue line: $\mathrm{ECRu}$; red line: VCRm; green line: ECRi.

\section{DISCUSSION}

The human lumbar spine has a short columnar shape, due to the flatness of the upper and lower endplates. In contrast, the upper endplates of deer and sheep slightly bulge and the lower endplates slightly sag, which results in a tall columnar shape.

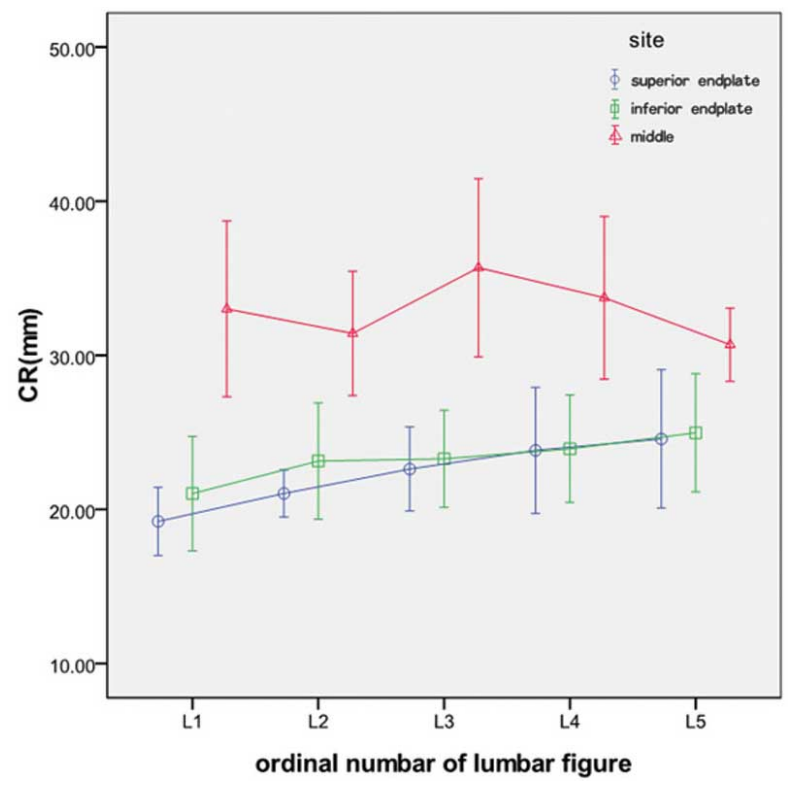

Fig. 11. Comparison of ECRu, ECRi, and VCRml of deer. Blue line: $\mathrm{ECRu}$; red line: VCRm; green line: ECRi.

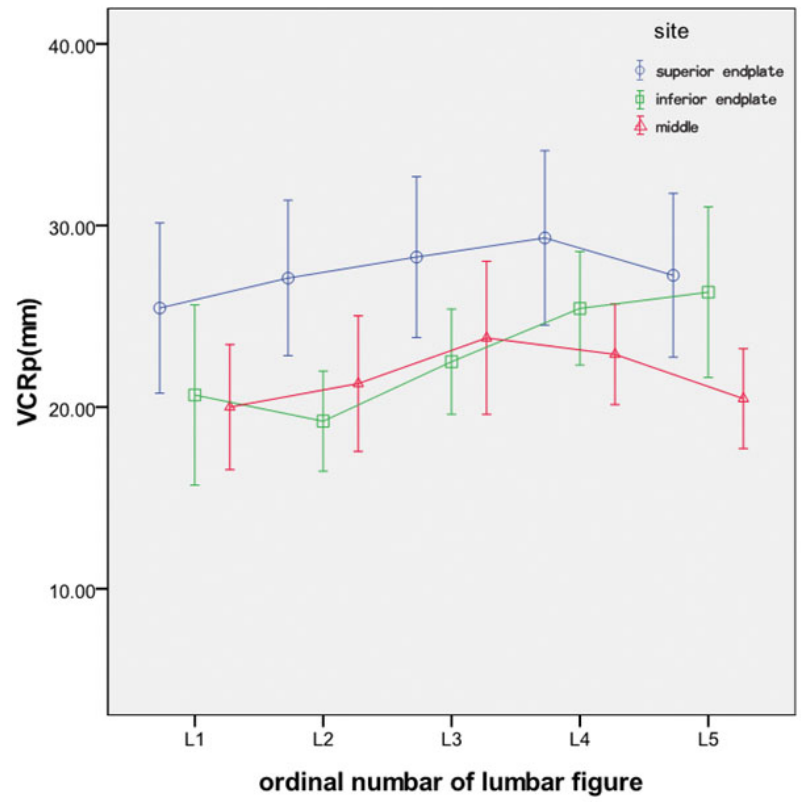

Fig. 13. Comparison of VCRp of human, deer, and sheep. Blue line: deer; red line: sheep; green line: human.

\section{Linear Measurements (Table II)}

VBH: For deer and sheep, VBHa was smaller than VBHp and the lumbar spine showed a ventral wedge type. The human lumbar vertebrae were tall in the front but short in the back from $\mathrm{L} 4$, which is the end of the lumbar spine flexure. We infer that the force direction of the lumbar vertebrae is anteroinferior above L4 and posteroinferior below L4 in human. 


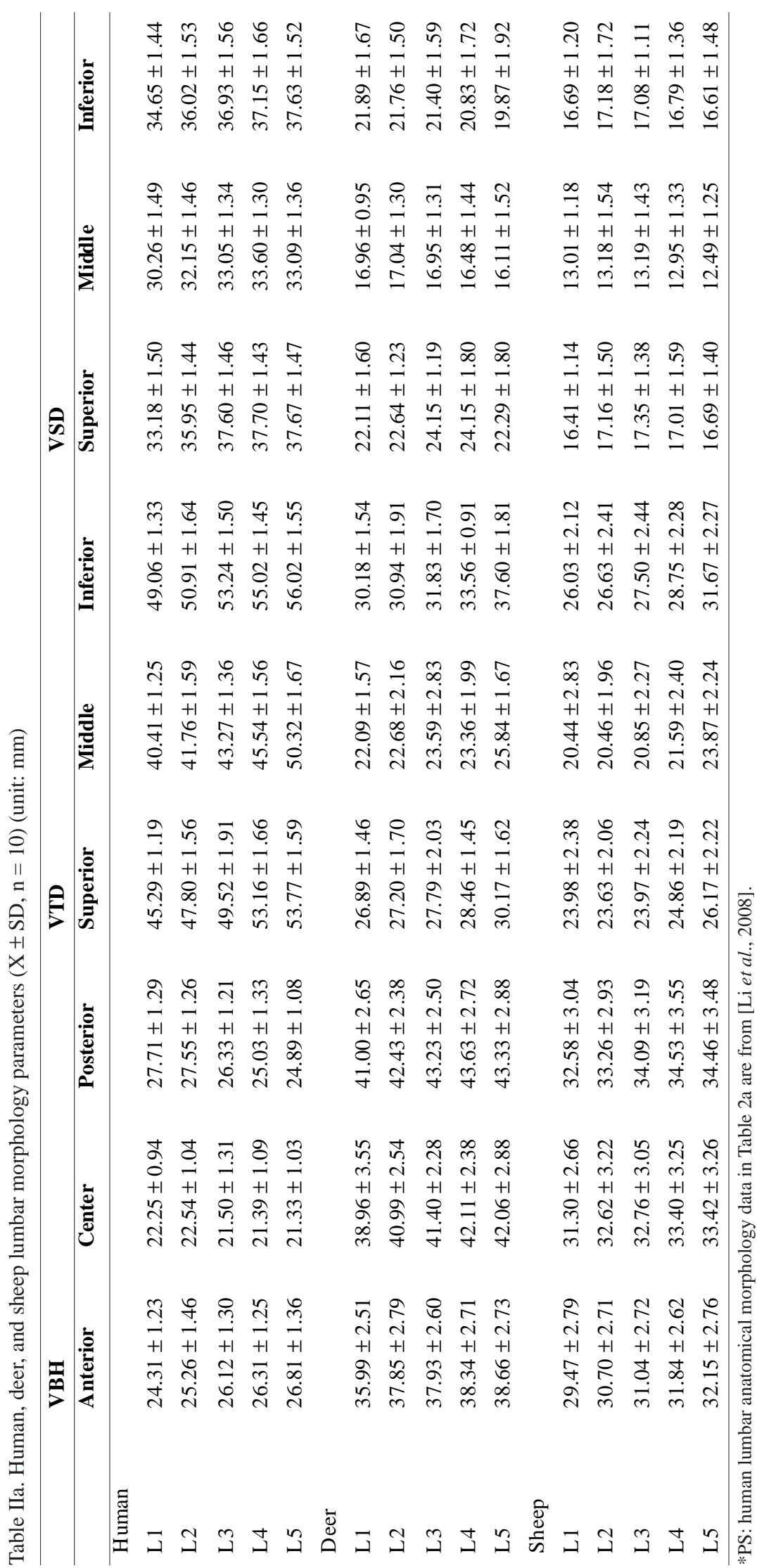

VSD: In human, VSDi was larger than VSDs in L1 and L2, which tended to increase the lumbar stability. VSDi was smaller than VSDs from L3 to L5, which tended to increase the lumbar flexibility. From L1 to L5, the VSDi values of the epistasy vertebrae were less than the VSDs values of the hypostasy vertebrae (Fig. 2). This condition diminished the contact area of the adjacent vertebrae and guaranteed good flexibility of the human lumbar spine segments.

The VSDs of deer gradually increased from L1 to L4, but decreased in L5. VSDi showed a gradually descending trend from L1 to L5. From L1 to L5, VSDi was smaller than VSDs; the VSDi values of the epistasy vertebrae were less than the VSDs values of the hypostasy vertebrae (Fig. 3). This condition diminished the overlap and coverage of adjacent vertebrae and increased the flexibility of the deer lumbar spine segments.

The VSD of the sheep lumbar vertebrae gradually increased from $\mathrm{L} 1$ to L3 but decreased from L4 to L5. The VSDi values of L1 and L2 were larger than the VSDs values; this condition tended to increase lumbar spine stability. The VSDi values were less than the VSDs values from L3 to L5; this condition tended to increase lumbar flexibility. The VSDi values of L1 and L2 were smaller than the VSDs values of the hypostasy vertebrae, which diminished the overlap and coverage of adjacent vertebrae and increased the flexibility of the lumbar spine segments. The VSDi values of L3 and L4 were larger than the VSDs values of the hypostasy vertebra. This situation increased the overlap and coverage of adjacent vertebrae and increased the stability of the lumbar spine segments (Fig. 4).

It is evident from these results that the values and variation tendencies of deer VSD are similar to those of the human lumbar spine. 
Table IIb. Human, deer, and sheep lumbar morphology parameters $(\mathrm{X} \pm \mathrm{SD}, \mathrm{n}=10)$ (unit: $\mathrm{mm}$ )

\begin{tabular}{lllll}
\hline \multicolumn{4}{c}{ Vertebral canal } & \multicolumn{3}{l}{ Pedicle (right) } \\
\hline Human & SCTD & SCSD & PDH & PDW \\
L1 & $21.86 \pm 1.08$ & $16.89 \pm 1.40$ & $16.06 \pm 0.66$ & $9.51 \pm 0.76$ \\
L2 & $22.08 \pm 1.14$ & $15.33 \pm 1.50$ & $16.63 \pm 0.70$ & $10.89 \pm 0.75$ \\
L3 & $22.75 \pm 1.07$ & $15.12 \pm 1.43$ & $15.82 \pm 0.85$ & $13.50 \pm 0.81$ \\
L4 & $23.76 \pm 1.20$ & $15.23 \pm 1.44$ & $15.20 \pm 0.99$ & $15.46 \pm 0.76$ \\
L5 & $26.56 \pm 1.18$ & $15.55 \pm 1.26$ & $14.90 \pm 0.97$ & $19.53 \pm 0.82$ \\
Deer & & & & \\
L1 & $14.81 \pm 0.81$ & $11.81 \pm 0.59$ & $31.97 \pm 1.99$ & $7.64 \pm 1.06$ \\
L2 & $14.91 \pm 0.88$ & $12.08 \pm 0.783$ & $34.32 \pm 2.20$ & $8.21 \pm 0.47$ \\
L3 & $15.45 \pm 0.78$ & $12.14 \pm 0.76$ & $34.87 \pm 2.21$ & $9.38 \pm 0.98$ \\
L4 & $16.55 \pm 1.05$ & $12.29 \pm 0.71$ & $35.16 \pm 2.90$ & $10.00 \pm 1.08$ \\
L5 & $18.79 \pm 1.40$ & $13.23 \pm 0.92$ & $34.96 \pm 2.76$ & $10.50 \pm 0.80$ \\
Sheep & & & & \\
L1 & $13.26 \pm 1.09$ & $8.83 \pm 0.75$ & $23.62 \pm 2.67$ & $6.36 \pm 0.65$ \\
L2 & $13.10 \pm 0.92$ & $8.75 \pm 0.63$ & $24.83 \pm 2.44$ & $6.42 \pm 0.76$ \\
L3 & $13.53 \pm 0.82$ & $8.91 \pm 0.65$ & $25.23 \pm 2.50$ & $6.72 \pm 0.66$ \\
L4 & $14.45 \pm 1.00$ & $9.24 \pm 0.63$ & $25.53 \pm 2.75$ & $6.95 \pm 0.54$ \\
L5 & $15.93 \pm 1.18$ & $9.94 \pm 0.73$ & $25.65 \pm 2.76$ & $7.52 \pm 0.82$ \\
\hline *PS: Human lumbar anatomical morphology data in Table IIb are from [Wang, 2007$].$
\end{tabular}

VTD: For human, the VTDi values were larger than the VTDs values. The VTDi values of the epistasy vertebrae were larger than the VTDs values of the hypostasy vertebrae, which increased the contact area of the adjacent vertebrae and increased the stability of the lumbar spine segments. The deer and sheep VTD values showed trends that were similar to those of human. Compared to the sheep lumbar spine, deer was closer to human in the VTD values. VSD and VTD are essential parameters when considering artificial intervertebral disc implants. Thus, deer are more suitable than sheep as a spinal animal model of artificial intervertebral discs.

Spinal canal: The SCTD of human gradually increased from L1 to L5. SCSD gradually decreased from L1 to L3 and slightly increased in L4 and L5. The variation tendency of the human lumbar spinal canal is consistent with lumbosacral enlargement of the spinal cord and cauda eguina. The SCTD and SCSD values of deer gradually increased from L1 to L5. The SCTD and SCSD values of sheep also gradually increased, except at L2.

Pedicle: PDW showed the same variation trend as VTD, gradually increasing from L1 to L5. This condition increased the pedicle stability and reinforced the mechanical joints of the anterior and posterior columns. PDH showed a descending trend from L1 to L5, which was consistent with VBHp. This scenario is advantageous for the loading of the spinal anterior and posterior columns, and improves the balance role of the pedicle as a lever. The function of the pedicle in human, as an orthograde creatire, is related to the special biomechanical function of the spine.

In deer and sheep, the PDW gradually increased from L1 to L5, showing a similar variation tendency as the human PDW. PDH gradually increased from L1 to L5, consistent with the variation tendency of VBHp. The PDW values showed a similar variation tendency in human, deer, and sheep. These results indicate that the pedicle stability was gradually increased with the increasing vertebral ordinal number, consistent with the load bearing of the lumbar spine (Fig. 5).

In contrast, the PDH of deer and sheep showed an increasing trend from L1 to L5, which is opposite to the variation tendency in human. With the transmission of gravity, the anterior and posterior columns of different lum- 

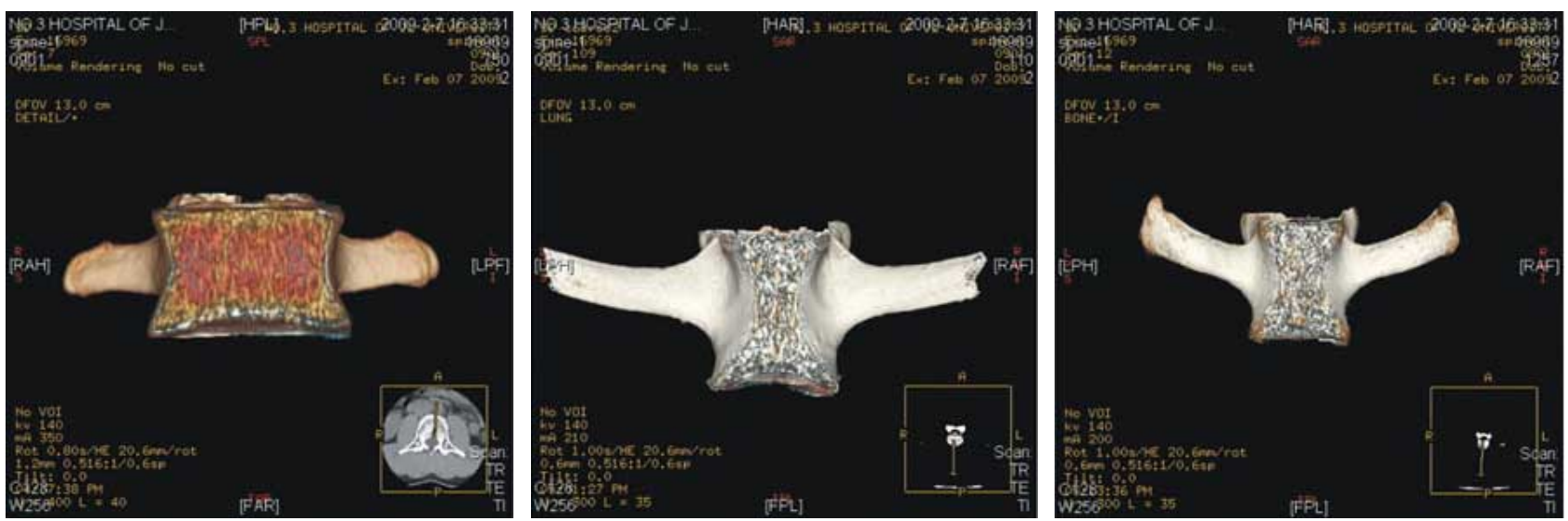

Fig. 14. VCRp of human, deer, and sheep.

bar spine segments bear different proportions of the total load. This response is related to the lever balance function of the pedicles. In the human lumbar spine, PDW gradually increases and PDH gradually decreases from L1 to L5. As a result, the pedicles tend to form a cylinder, thus enhancing the mechanical property of the pedicles and improving their regulation of loading balance.

In contrast, the PDW and PDH of both deer and sheep show gradually increasing trends from L1 to L5. Consequently, the stability of the pedicles gradually increases with increasing vertebral ordinal number, but the pedicles do not play an obvious role as a lever. The reason for this inconsistency between human and sheep/deer is probably due to the different walking styles of the species and the consequently different mechanical functions.

In posterior lumbar spinal surgery, PDW and PDH determine the diameter of the pedicle screw and the location of the implanting screw, respectively. VSD and VTD determine the length of the pedicle screw and the angle of tilt of the implanting screw, respectively. According to the linear measurement parameter of the lumbar vertebrae, the deer and human lumbar spines are similar.

Table III. Human, deer, and sheep lumbar curvature radii (X $\pm \mathrm{SD}, \mathrm{n}=10$ ) (unit: $\mathrm{mm}$ )

\begin{tabular}{|c|c|c|c|c|c|}
\hline & ECRu & ECR1 & VCRml & VCRp & VCRl \\
\hline \multicolumn{6}{|c|}{ Human } \\
\hline L1 & $21.29 \pm 1.33$ & $22.73 \pm 1.41$ & $19.24 \pm 1.64$ & $20.67 \pm 4.96$ & $36.14 \pm 5.48$ \\
\hline $\mathrm{L} 2$ & $22.15 \pm 1.28$ & $23.34 \pm 1.82$ & $19.16 \pm 1.91$ & $19.23 \pm 2.75$ & $36.50 \pm 3.82$ \\
\hline L3 & $23.02 \pm 2.03$ & $23.84 \pm 2.75$ & $19.94 \pm 1.07$ & $22.50 \pm 2.89$ & $38.39 \pm 6.72$ \\
\hline L4 & $23.16 \pm 1.08$ & $23.81 \pm 1.28$ & $20.48 \pm 1.89$ & $25.44 \pm 3.12$ & $39.74 \pm 5.75$ \\
\hline L5 & $24.18 \pm 3.13$ & $25.17 \pm 1.35$ & $24.08 \pm 3.32$ & $26.33 \pm 4.70$ & $47.10 \pm 4.89$ \\
\hline \multicolumn{6}{|c|}{ Deer } \\
\hline L1 & $19.22 \pm 2.21$ & $21.03 \pm 3.72$ & $33.01 \pm 5.70$ & $25.46 \pm 4.68$ & $21.93 \pm 1.74$ \\
\hline L2 & $21.04 \pm 1.53$ & $23.14 \pm 3.78$ & $31.42 \pm 4.03$ & $27.11 \pm 4.28$ & $21.51 \pm 1.43$ \\
\hline L3 & $22.62 \pm 2.73$ & $23.28 \pm 3.15$ & $35.69 \pm 5.78$ & $28.26 \pm 4.43$ & $19.15 \pm 3.36$ \\
\hline L4 & $23.83 \pm 4.09$ & $23.93 \pm 3.49$ & $33.73 \pm 5.27$ & $29.32 \pm 4.80$ & $21.78 \pm 3.39$ \\
\hline L5 & $24.57 \pm 4.49$ & $24.97 \pm 3.83$ & $30.69 \pm 2.38$ & $27.26 \pm 4.51$ & $23.07 \pm 4.02$ \\
\hline \multicolumn{6}{|c|}{ Sheep } \\
\hline L1 & $14.75 \pm 2.81$ & $14.99 \pm 2.64$ & $41.57 \pm 6.36$ & $20.01 \pm 3.45$ & $28.59 \pm 4.46$ \\
\hline L2 & $14.71 \pm 2.23$ & $16.01 \pm 2.77$ & $31.04 \pm 3.16$ & $21.30 \pm 3.74$ & $23.19 \pm 3.06$ \\
\hline L3 & $14.88 \pm 2.63$ & $17.08 \pm 3.91$ & $23.08 \pm 5.12$ & $23.81 \pm 4.21$ & $22.46 \pm 3.61$ \\
\hline L4 & $15.53 \pm 2.80$ & $17.18 \pm 3.54$ & $20.30 \pm 2.80$ & $22.91 \pm 2.77$ & $22.67 \pm 3.90$ \\
\hline L5 & $16.97 \pm 4.24$ & $19.21 \pm 4.41$ & $21.39 \pm 3.43$ & $20.47 \pm 2.75$ & $23.24 \pm 3.97$ \\
\hline
\end{tabular}




\section{Vertebral Morphology Index}

CVI: In human and sheep, the CVI was triangular. The CVI of deer lumbar spine tended to be circular from L1 to L4 and triangular in L5.

PAR: In the human lumbar spine, the PAR values of $\mathrm{L} 1$ and L2 were triangular, L3 tended to be circular, while L4 and L5 were subcircular. This variation is consistent with the variation tendency of PDW and PDH, as well as with the mechanical support effect and lever balance function of the pedicles. The PAR values of deer and sheep were board-form; PAR showed a slowly increasing trend with increasing vertebral ordinal number (Fig. 6).

\section{Curvature Radius (Table III)}

ECRu, ECRl, and VCRml: The ECRu and ECRl values of deer were similar to those of human (Figs. 7 and 8). The human lumbar spine upper and lower curvature radii increased with increasing vertebral ordinal number, and ECRl was larger than ECRu in all lumbar vertebrae (Fig. 10). The ECRu and $E C R 1$ values of deer and sheep increased with increasing vertebral ordinal number, and ECRi was larger than ECRu (Figs. 11 and 12).

Human VCRml was less than ECRu or ECRl and gradually increased from L1 to L5 (Fig. 10). The curves of ECRu, ECRl, and VCRml gradually converged from L1 to L5, demonstrating the variation tendency of human ECRu and ECRl with the increasing ordinal number of the lumbar vertebrae.

Overaker et al. (1999) studied the relationship between the vertebral lateral wall curvature and vertebral load-bearing capacity. They reported that the loading limit decreased as the vertebral lateral wall curvature radius increased. We believe that a cylinder-shaped vertebra with similar upper, middle, and lower curvature radii has the best load-bearing capacity. The human upper vertebrae act like middle concave short columns. As gravity is transmitted from top to bottom (L1 to L5), the loading on the lumbar spine gradually increases. To adapt to this variation in loading, the lumbar spine gradually translates into a cylinder.

The VCRml of the deer lumbar spine was larger than ECRu or ECRl in all levers, and roughly decreased from L1 to L5 (Fig. 11). For the deer and sheep lumbar spine, the CR of the upper, middle, and lower levers changed with the increasing vertebral ordinal number. The curves showed an obvious tendency to converge from L1 to L5. The sheep lumbar spine was similar to human in the variation tendency of VCRml and in the relationship between ECRu and ECRl.
Compared to deer, the VCRml of the sheep lumbar spine was closer to that of human (Fig. 9). The VCRml values of human and sheep from L3 to L5 were not significantly different from each other (variance analysis, $\mathrm{P}>0.05$ ).

VCRp: The human VCRp showed a roughly increasing trend from L1 to L5, consistent with the variation tendency of the upper, middle and lower lever curvature radii and the research results of Overaker et al. This finding probably is related to the increase in load-bearing from top to bottom. Similar to human, VCRp increased from L1 to L4 in deer and from L1 to L3 in sheep. The sheep VCRp was closer to the human VCRp than was deer. There was an obvious decrease in deer VCRp at L5 and sheep VCRp at L4 and L5 compared to the epistasy vertebrae, consistent with the variation in the deer and sheep VSD values (Figs. 13 and 14).

The curvature radius is an important factor in anterior spinal anatomical fixation surgery, as it determines the shape of the plate. In the anterior spinal animal model, the sheep has the obvious superiority over deer in similarity to human.

CONCLUSION. According to the parameters for the lumbar vertebral anatomical morphology, the sheep lumbar spine is closer to human in terms of $\mathrm{VBH}$ and $\mathrm{PDH}$, while the deer lumbar spine is closer to human in terms of VTD, VSD, and PDW. The vertebral morphology index results indicate that deer and sheep lumbar spines each have good similarity to human.

Due to the different force-bearing styles of human, deer, and sheep spines, the species showed differences in their pedicle morphologies. The variation tendencies of the various vertebra curvature radii reflected the variation characteristics of vertebral loading. Based on the lumbar spine morphology curvature radii, both deer and sheep lumbar spines had variation tendencies that were similar to those in human. The ECRu and ECRl values of deer were more similar to human than were sheep, with no statistically significant difference between deer and human. In terms of the VCRml and VCRp results, the sheep lumbar spine showed more obvious similarity to human than deer, and no statistically significant difference was found between sheep and human.

We conclude that the deer lumbar spine has a good similarity to human in terms of the vertebral upper and lower endplate regions, suggesting that a deer spinal model would be applicable for studying artificial intervertebral discs, artificial nucleus gelatinosus, implantion of intervertebral fusion, etc. The sheep lumbar spine is more similar to human in terms of the vertebral lateral wall, suggesting that a sheep spinal model would be applicable for studying steel-board fixation. 
BAI, X.; LIU, G.; XU, C.; ZHUANG, Y.; ZHANG, J.; JIA, J. \& LIU, Y. Investigación morfometríca de la columna vertebral lumbar de ciervos, ovejas y humanos: factibilidad del uso de ciervos y ovejas como modelos animales de columna vertebral. Int. J. Morphol., 30(2):510$520,2012$.

RESUMEN: Los ciervos y las ovejas se utilizan como modelos animales para la investigación clínica y básica de columna vertebral. En este trabajo, fueron investigados parámetros de morfología anatómica, curvatura e índice morfológico para evaluar la viabilidad de la utilización de ciervos y ovejas como modelos animales de la columna vertebral humana. Fueron examinados y sometidos a análisis morfológicos, especímenes frescos de columna vertebral ( $\mathrm{n}=10$ cada uno) de ovejas y ciervos machos adultos, y columnas de individuos adultos humanos, de sexo masculino. Se utilizó el programa estadístico SPSS (versión 17.0) para analizar la similitud estadística y la variabilidad entre las 3 especies. Los ciervos muestran similitud con el humano en términos del diámetro vertebral transversal, vector radio, diámetro del canal espinal transversal, vector radio, y los radios de curvatura vertebral superior e inferior de la placa terminal. Las ovejas muestran similitud con el humano en cuanto a la altura del cuerpo vertebral, altura del pedículo, curvatura de radio vertebral medio, y el radio de curvatura vertebral positiva. Los humanos, ciervos y ovejas muestran características morfológicas y direcciones de la columna vertebral únicas. Estos hallazgos indican que los ciervos y las ovejas son buenos modelos animales en la morfometría de la columna vertebral humana, pero con ventajas específicas en diferentes campos de investigación: los ciervos son más adecuados en el estudio de las vértebras y las estructuras de placa terminal, mientras que las ovejas son más adecuados cuando se refiere a estructuras como las paredes vertebrales.

PALABRAS CLAVE: Columna vertebral; Modelo animal; Humano; Ciervos; Ovejas; Morfometría.

\section{REFERENCES}

Bai, H.; Chen, W.; Dai, L. \& Zhang, M. The sagittal and transverse diameters of Chinese spinal canal. Acta Anat. Sin., 11:261, 1980.

Christensen, F. B.; Dalstra, M.; Sejling, F.; Overgaard, S. \& Bünger, C. Titanium-alloy enhances bone-pedicle screw fixation: mechanical and histomorphometrical results of titanium-alloy versus stainless steel. J. Eur. Spine, 9(2):97-103, 2000.

Kettler, A.; Liakos, L.; Haegele, B. \& Wilke, H. J. Are the spines of calf, pig and sheep suitable models for pre-clinical implant tests? Eur. Spine J., 16(12):2186-92, 2007.

Kumar, N.; Kukreti, S.; Ishaque, M. \& Mulholland, R. Anatomy of deer spine and its comparison to the human spine. Anat. Rec., 260(2):189-203, 2000.

Matsuzaki, H.; Numabe, T.; Tokuhashi, Y.; Wakabayashi, K.; Ishihara, K.; Shirasaki, Y. \& Tateishi, T. Evaluation of hydroxyapatite-coated screws for lumbar spine fixation in dogs. J. Orthop. Sci., 2(6):405-13, 1997.

National Standards for Laboratory Animals. People's Republic of China National Science and Technology Committee. State Bureau of Technical Supervision, China, 1997.

Overzker, D. W.; Langrana, N. A. \& Cuitino, A. M. Finite element analysis of vertebral body mechanics with a nonlinear microstructural model for the trabecular core. J. Biomech. Eng., 121(5):542-50, 1999.

Qiao, S. \& Han, X. Morphologic measure of the pediculus arcus verebrae of the thoracic ver-tebrae and its clinical significance. Chin. J. Clin. Anat., 14(3):193-5, 1996.
Sandén, B.; Olerud, C. \& Larsson, S. Hydroxyapatite coating enhances fixation of loaded pedicle screws: a mechanical in vivo study in sheep. Eur. Spine J., 10(4):334-9, 2001.

Schimandle, J. H. \& Boden, S. D. Spine update. Animal use in spinal research. Spine, 19(21):2474-7, 1994.

Seldin, E. D. \& Hirsch, C. Factors affecting the determination of the physical properties of the femoral cortical bone. Acta Orthop. Scand., 37(1):29-48, 1966.

Shao, X. Q. Anthropometry Manual.Shanghai. Shanghai Lexicographical Publishing House, 1985. pp.135-8.

Vialle, R.; Dauzac, C.; Khouri, N.; Wicart, P.; Glorion, C. \& Guigui, P. Sacral and lumbar-pelvic morphology in high-grade spondylolisthesis. Orthopedics, 30(8):642-9, 2007.

Wilke, H. J.; Kettler, A.; Wenger, K. H. \& Claes, L. E. Anatomy of the sheep spine and its comparison to the human spine. Anat. Rec., 247(4):542-55, 1997.

Yildirim, O. S.; Aksakal, B.; Hanyaloglu, S. C.; Erdogan, F. \& Okur, A. Hydroxyapatite dip coated and uncoated titanium poly-axial pedicle screws: an in vivo bovine model. Spine, 31(8):215-20, 2006

Correspondence to:

Yi Liu

Department of Orthopedics

The Second Hospital of Jilin University

No. 218Ziqiang Road, Changchun 130041

CHINA

Tel: +86-0431-88796673

Fax: +86-0431-88910305

Email: yutong160@sina.com

Received: 15-10-2011

Accepted: 10-01-2012 